\title{
A Multidimentional Study on Entrepreneurial Opportunity Recognition of College Students under the Era of Internet Plus
}

\author{
LIU Xiong \\ Wuhan Textile University, Wuhan, 430073, China \\ email: Ix@wtu.edu.cn
}

\begin{abstract}
Key words: Internet plus; entrepreneurial opportunity recognition; entrepreneurial alertness; social network
\end{abstract}

\begin{abstract}
To encourage university students' innovative undertaking is an important way to ease the employment pressure. For this, university students should at first be provided with the capability to recognize entrepreneurial opportunity. To train students for this capability, it is vital for universities and the society to optimize the model of course teaching, to construct the platform of entrepreneurial practice and to open up the ways for association, so that university students can seize the opportunity to start up their own business.
\end{abstract}

\section{Introduction}

On March $5^{\text {th }}, 2015$, premier Li raised the plan of Internet plus in Chinese government work report. He claimed that the economic growth should be innovation-driven. For example, the traditional industries can be closely combined with the mobile Internet, cloud computing, big data and Internet of Things. [1] Moreover, Chinese government encourages the public to make the best of the new generation of information technology as well as the innovation opportunity to start up business and stir up the vitality of markets and the society. With the popularization of the Internet in China, different industries have brought about great opportunity for development. Faced with a tough job market, a number of graduates take up the marketing campaign with the help of the Internet. [2] However, the entrepreneurial opportunity recognition is merely the initial period, which is a significant source of the entrepreneurial capability and competitive edge. [3] Therefore, how to cultivate undergraduates the capabilities to identify entrepreneurial opportunity and guide them to the right track is a task for not only the entrepreneurs but the colleges, the government and the whole society to think highly of.

\section{Problems of entrepreneurial opportunity recognition among college students}

\section{A. The limitation of knowledge structure}

First of all, the undergraduates need to synthetically judge a variety of complex entrepreneurial information for the recognition of entrepreneurial opportunity. And the premise is that entrepreneurs should have solid professional knowledge and subsidiary working skills to form a more systematic knowledge hierarchy. [4] If undergraduates only value the specialized knowledge and overlook some others indispensable like marketing, finance, legal, tax, etc., they will not find valuable information, resulting in a lack of novel and systematic ideas about entrepreneurship. In the stage of the entrepreneurial opportunity evaluation, if the undergraduates do not possess a thorough knowledge structure, it will be difficult for them to combine a comprehensive knowledge of economics, operations research, and statistics with the entrepreneurial opportunity. Then the profitability, feasibility and even the risks can not be properly predicted and accessed, leading to the 
failure of entrepreneurship.

\section{B. The lack of entrepreneurial alertness}

The entrepreneurial alertness means that the information from objects, events and behaviors contains sensibility, which reflects the continuous attention to the opportunity yet to be discovered. As a matter of fact, there is few undergraduates have entrepreneurial alertness. Compared with those who have entrepreneurial alertness, these students usually lack the capability of market risk perception, of interpersonal relationship and of judgment, which are not available from the school textbooks.[5] This knowledge can only be acquired through the improvement of knowledge and enough practice. Therefore, in the face of the same opportunity, the undergraduates usually cannot keenly grasp the entrepreneurial opportunity at the early stage owing to the lack of entrepreneurial experience.

\section{The weakness of social network}

Apart from a complete stock of knowledge of the entrepreneur him/herself, the social network for the individual is very important as well. On the one hand, undergraduates' capability to identify the entrepreneurial opportunity is affected by their knowledge structure and experience through practice established in college. On the other hand, it is affected by their social network. Most of the social network of students is from their everyday life, mainly established through professional learning, leisure activities, and social gatherings. [6] The network of a person is closely related to one's preference; also, the establishment and dissipation of social networks have arbitrariness. After the undergraduates make up their mind to start up business, they will demand enough entrepreneurial information and market resources. Then the social network will be of no use if it is for their daily study and service of living.

\section{The theoretical overview of entrepreneurial opportunity recognition}

\section{A. The process of entrepreneurial opportunity recognition}

The process of entrepreneurship starts from the recognition of opportunity. New Austrian School representative Kirzner thinks that entrepreneurial opportunity recognition on the one hand is to obtain by pure chance, on the other hand is through the purposeful search. [7] The process of opportunity recognition not only refers to the market of pure chance, but also refers to entrepreneurs use prior knowledge and experience, over a period of time they search and are alert to find the information which are ignored by others. With this information, they do the information carding, screening and evaluation, and finally recognize the entrepreneurial opportunities. It deserves the individual to possess some theoretical knowledge, entrepreneurial alertness and social network. Among many complex innovations, the entrepreneur chooses the one up to his/her mind, and then attempts to develop this opportunity and makes it the start of business. During the process, the prospective value of the opportunity will be weighed repetitively, and the entrepreneur will be much more experienced. This process is called opportunity recognition. The model is shown in Figure 1.

Figure1 The model of entrepreneurial opportunity recognition 


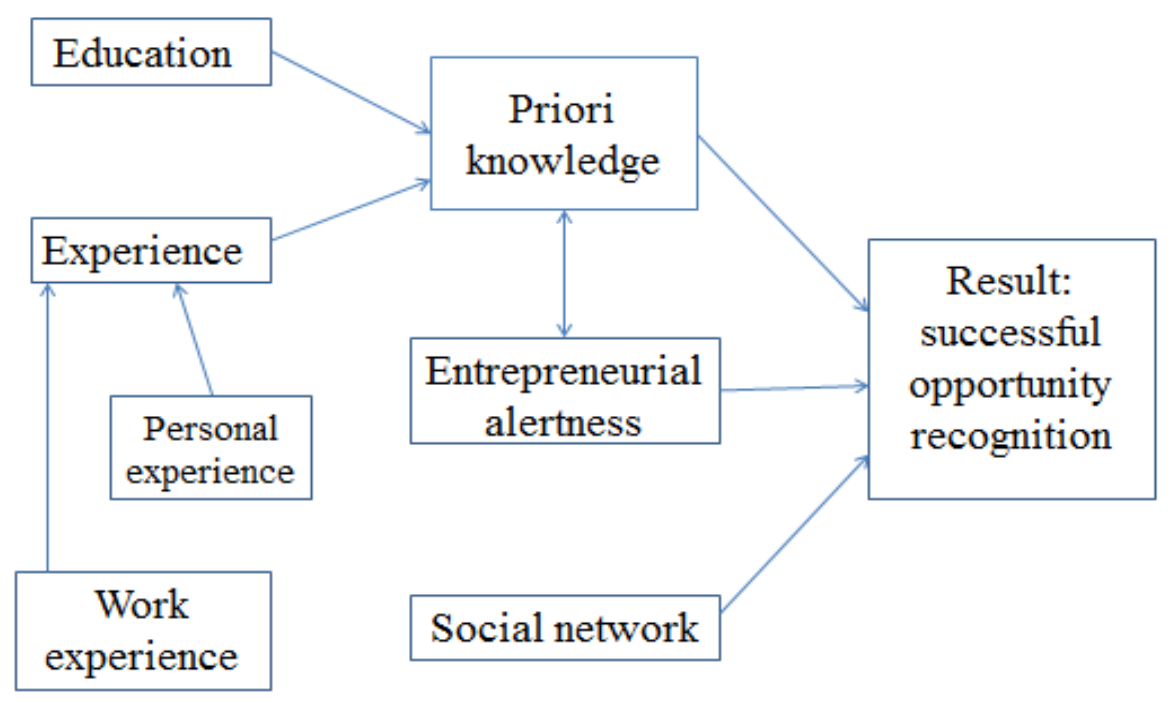

B. The principal factors that influence entrepreneurial opportunity recognition

Firstly, it is the priori knowledge. Priori knowledge is the knowledge or experience that an entrepreneur acquired from previous study or work. Different people with different life experience may have different priori knowledge. Generally speaking, it mainly contains three aspects: the theoretical knowledge through study or training; the experience from previous entrepreneurship and the industry experience accumulated from internship, part-time jobs or work. Many researches have found that the entrepreneurial opportunity recognized by the entrepreneur has much to do with his/her experience or skills accumulated from previous study or work.

Secondly, it is the entrepreneurial alertness. This is a key factor to one's success. Entrepreneurial alertness is a personal ability which helps the entrepreneur recognize some opportunities yet to be detected. Only when the undergraduates are provided with entrepreneurial alertness, can they successfully dig out the entrepreneurial opportunity and make the best of it. Usually it is believed that open and optimistic characteristic can help improve people's entrepreneurial alertness.

Thirdly, it is the social network. Social network is closely related to where the entrepreneurial information comes from. It is a structure unit constituted owing to interrelation among people, which loads some related information, knowledge and various social feelings. At the start-up, the entrepreneur is often strongly influenced by his/her social network when he/she makes decisions, because the entrepreneur need the information provided by the social network to broaden his/her horizon. The approaches to improve entrepreneurial opportunity recognition

A. Optimizing the course teaching model and improving the knowledge structure of college students

Influenced by the employment pressure in recent years, many colleges have offered the entrepreneurship education courses. Students can take up such courses if interested. Nevertheless, the elective courses cannot totally change the situation because the entrepreneurial opportunity 
recognition requires students to have a thorough knowledge structure. The Internet technology is widely spread in colleges. For example, the Internet plus education, like Learning Manager System, E-learning Platform, Moocs and Microlecture have impressed the students a lot, which plays a positive role to the transformation of the entrepreneurial education in colleges.

Colleges should bring students' professional knowledge, general education knowledge, business knowledge and network technology into the curriculum system. Moreover, they should make an introduction to the new policies and new models in the field of Internet. Not only should we have a relatively stable informative content such as "innovation and entrepreneurship", "new enterprise management”, “opportunities and risk assessment”, but also a relative change in policies, such as "entrepreneurship policy changes and interpretation", "face to face entrepreneurial hot spots". With these two contents, students will be eager enough to learn the correlated curriculum.

B. Setting up the platform of entrepreneurial internship and training the entrepreneurial alertness

Through the analysis of the successful case of university entrepreneurs, it is found that those who have strong cognitive abilities usually are more likely to recognize and grasp the market opportunity. The strong cognitive abilities come from one's personality traits and the knowledge of a certain field. To cultivate college students' entrepreneurial alertness, a variety of channels need to be provided with to make them be familiar with the entrepreneurial process. The colleges, enterprises and the government should work together to set up the "Internet plus" entrepreneurial practice platform for students. In addition, they should provide human resources, goods, policy information and market information.

Besides, research technicians should be arranged to guide students. Colleges also can hold some activities like innovative entrepreneurship competition and business simulation and encourage students to participate in.[8] Through the rich and colorful "Internet plus" innovative entrepreneurial activities, students' spirit of innovation, pioneering consciousness and innovation abilities will be improved.

C. Expanding the social network of college students

Social network is one of the most important ways for entrepreneurs to successfully identify entrepreneurial opportunities, and it directly affects the business development and the social resources. A sound network can strengthen information communication and guarantee successful business. However, the traditional education mainly includes intellectual education and professional knowledge education and neglects emotional education and the education for interpersonal skills.

In the era of "Internet plus", colleges should update education concepts. For example, they can bring emotional education and interpersonal education into the university curriculum system through some social classes or lectures. Also, they can encourage students to participate in a variety of student community organizations in order to strengthen the communication among the students and create their own social network. 
Additionally, teachers can encourage students to join their scientific research team to promote the interaction and communication between teachers and students. Some social media (like weibo, WeChat) should be attached to great importance. Colleges can gather the students who share the same entrepreneur dream together through the convenient social media. The students in the same group can participate in the topic discussion. Therefore, not only can their friendship be enhanced but also they will have a convenient access to some relevant information.

\section{Conclusion}

The era of Internet plus not only has brought about some new opportunities to the transformation of traditional industries, but also has provided the undergraduates with great chances to their entrepreneurial innovation. The sophisticated market environment requires the university entrepreneurs to improve their skills of opportunity recognition, broaden their horizons and practice their independent thinking capacity. It is definite that good market opportunity is difficult to find or grasp. However, all the entrepreneurs should be the opportunists. If their capability of entrepreneurial opportunity recognition is improved, they will grasp the market opportunity and establish a solid foundation for their success.

\section{References}

[1] Luigi Atzori,Antonio Iera,Giacomo Morabito. The Internet of Things: A survey[J]. Computer Networks . 2010 (15)

[2] JohnPaolillo. The Virtual Speech Community: Social Network and Language Variation on IRC[J]. Journal of Computer - Mediated Communication. 2006 (4)

[3] Deniz Ucbasaran,Paul Westhead,Mike Wright. The extent and nature of opportunity identification by experienced entrepreneurs[J]. Journal of Business Venturing . 2008 (2)

[4] Joep P Cornelissen,Jean S Clarke.Imagining and Rationalizing Opportunities: Inductive Reasoning and the Creation and Justification of New Ventures. The Academy of Management Journal . 2010

[5] Robert A. Baron,Michael D. Ensley. Opportunity Recognition as the Detection of Meaningful Patterns: Evidence from Comparisons of Novice and Experienced Entrepreneurs[J]. Management Science . 2006

[6] HelenaYli - Renko,ErkkoAutio,Harry J.Sapienza. Social capital, knowledge acquisition, and knowledge exploitation in young technology - based firms[J]. Strat. Mgmt. J. 2001 (6 - 7)

[7] DimoDimov. Grappling With the Unbearable Elusiveness of Entrepreneurial Opportunities[J]. Entrepreneurship Theory and Practice . 2011 (1)

[8] Igor Kalinic,Saras D. Sarasvathy,Cipriano Forza. 'Expect the unexpected': Implications of effectual logic on the internationalization process[J]. International Business Review . 2013 